Bull. Egypt. Soc. Physiol. Sci. 40(2), 1-15

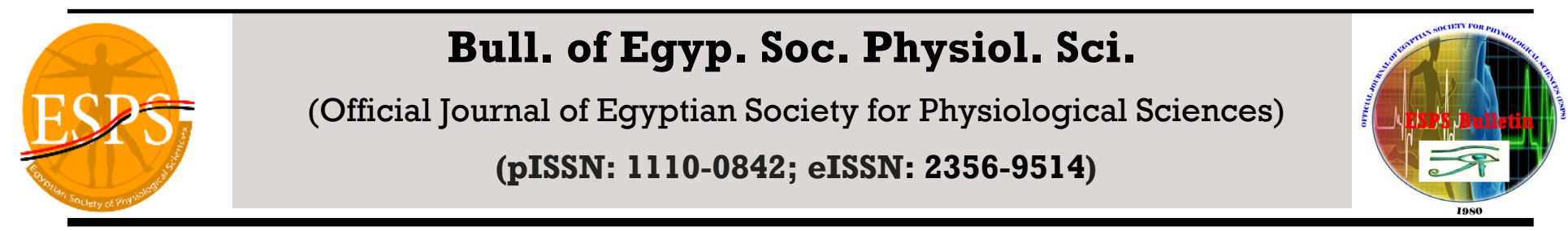

\title{
The Role of Hydrogen Sulfide in Chronic Unpredictable Stress-Induced Gastric
}

\section{Lesions}

\section{Mahmoud El Tohamy $^{* 1}$, Mohammad Ghalwash ${ }^{1}$, Nisreen M. Abo-Elmaaty ${ }^{1}$, Refka Messiha ${ }^{1}$, Samah Fouad $^{2}$}

Received: 28 August, 2019

Accepted: 22 Nov, 2019

Available online: 1 July, 2020

\section{Keywords}

- hydrogen sulfide $\left(\mathrm{H}_{2} \mathrm{~S}\right)$

- Chronic unpredictable stress (CUS)

- Caspase 3

- BCL-xl

${ }^{1}$ Department of Medical Physiology, Faculty of Medicine, Mansoura University, Egypt.

${ }^{2}$ Medical experimental research center, Mansoura University, Egypt.

\section{Abstract}

The aim of this study was to investigate the possible protective role of Hydrogen sulfide $\left(\mathrm{H}_{2} \mathrm{~S}\right)$ on chronic unpredictable stress (CUS) -induced gastric lesions in rats. Materials and methods: 40 rats were divided into 4 groups: control group, stressed rats group, stressed + Aminooxyacetic acid (AOAA) (inhibitor of $\mathrm{H}_{2} \mathrm{~S}$ synthesis; $50 \mathrm{mg} / \mathrm{kg} / 48$ hour; IP), stressed + Sodium hydrosulfide (NaHS) (donor of $\mathrm{H}_{2} \mathrm{~S}, 5 \mathrm{mg} / \mathrm{kg} / 48$ hour; IP). In all the groups exposed to CUS, a set of chronic unpredictable stressors was applied for 6 weeks in random order. At the end of experimental protocol blood samples, gastric content and gastric tissues samples were collected. Gastric tissues histopathological changes were evaluated by macroscopic and microscopic examination. Gastric content pH, serum MDA level, whole blood GSH level were estimated. Expression of Caspase-3 (apoptotic marker) and BCL-xl (anti-apoptotic marker) was assessed by immunohistochemistry. Results: In all the groups exposed to CUS, there was a significant reduction in gastric $\mathrm{pH}$ value and a range of gastric lesions ranging from superficial to deep ulceration as evident by macroscopic and microscopic examination. Also, there was significant elevation in MDA serum level and significant reduction in anti-oxidant GSH blood level. In all stressed rats, the expression of Caspase-3 was significantly higher whereas a significant decrease in expression of anti-apoptotic protein BCL-xl was observed. These findings were aggravated by AOAA while using NaHS improved them. Conclusion: it seems that increasing bioavailability of $\mathrm{H}_{2} \mathrm{~S}$ could have a protective role against CUS induced gastric lesions. The results suggest that this protection could be through anti-oxidant and anti-apoptotic effects 


\section{INTRODUCTION}

The role of stressful life events in the etiology of various human diseases has been a fertile field of research during the last three decades [1]. It has been increasingly recognized that stress is one of the important components of several diseases including hypertension and coronary heart disease, immunosuppression, metabolic disorders, reproductive dysfunction, mental depression, anxiety, loss of memory and many other organ injury diseases [2].

Several studies have reported that stomach is one of the main targets of repeated chronic stress [3, 4]. Indeed, different stress-related mucosal pathologies have been described in patients, including gastric mucosal damage, ulceration, and bleeding and were responsible for considerable morbidity and mortality in critically ill patients [5, $6]$.

On the other hand, Hydrogen sulfide $\left(\mathrm{H}_{2} \mathrm{~S}\right)$, a traditionally known toxic gas, is now known as a third gasotransmitter after nitric oxide and carbon monoxide [7]. Endogenous $\mathrm{H} 2 \mathrm{~S}$ is formed largely by the enzyme cystathionine $\beta$-synthase (CBS) in the nervous system cells, and cystathionine $\gamma$-lyase (CSE) in other organic cells, utilizing 1-cysteine and/or homocysteine as substrate [8]. Also, it has been reported that gastrointestinal tissues are capable of endogenous production of $\mathrm{H} 2 \mathrm{~S}$ which acts in these tissues as a gaseous signaling molecule [9].

A protective role of $\mathrm{H}_{2} \mathrm{~S}$ in different tissues has been postulated [10]. The stomach is one organ where $\mathrm{H}_{2} \mathrm{~S}$ has been reported to exert a protective role against gastric injury by several mechanisms [10]. One of these mechanisms could be cell apoptosis. It has been reported that $\mathrm{H}_{2} \mathrm{~S}$ exerts its protective effect in nervous tissue and circulatory system through anti apoptotic effect $[11,12]$. Therefore, the aim of the present work is to further investigate whether $\mathrm{H} 2 \mathrm{~S}$ has a protective role in stress-induced gastric lesions and the possible underlying mechanism.

\section{Material \&methods:}

This study was conducted on 40 adult male Sprague-Dawley rats weighing 150-200 grams. Animals were bred and housed in the animal house of Medical Experimental Research Center (MERC). The animals were divided into 4 experimental groups; (10 rats in each group), as follows: Group I(control group); in which the rats were maintained on standard rat chow with free access to water ad libitum for 6 weeks, Group II (stressed rats); in which the rats were exposed to chronic unpredictable stress for 6 weeks, Group III (stressed + AOAA); in which while the rats were exposed to chronic unpredictable stress, they received aminooxyacetic acid (AOAA), an Inhibitor of $\mathrm{H}_{2} \mathrm{~S}$ synthase enzymes, at a dose of $50 \mathrm{mg} / \mathrm{kg} / 48$ hour by IP injection for 6 weeks [13], Group IV (stressed + NaHS); in which while the rats were exposed to chronic unpredictable stress, they received Sodium hydrosulfide (NaHS), a $\mathrm{H}_{2} \mathrm{~S}$ donor ,at a dose of $5 \mathrm{mg} / \mathrm{kg} / 48$ hour by IP injection for 6 weeks [13].

\section{Chronic Unpredictable Stress (CUS) Protocol:}

A set of recognized chronic unpredictable stressors were used. Those stressors include: Cage tilting and damp sawdust for $24 \mathrm{~h}$, Noises for $1 \mathrm{~h}$ (alternative periods of $60 \mathrm{~dB}$ noise for $10 \mathrm{~min}$ and 10 min of silence), Swimming in $4{ }^{\circ} \mathrm{C}$ cold water for $5 \mathrm{~min}$,Water deprivation for $24 \mathrm{~h}$, Restricted movement for $4 \mathrm{~h}$ by placing the rats in small 
cages with limited space for movements and strong illumination during the predicted dark phase.One stressor was applied per day, and the whole chronic unpredictable stress procedure lasted for 6 weeks with a completely random order $[4,14]$.

After the application of the last stressor on the last day of the $6^{\text {th }}$ week of the CUS protocol, rats were fasted overnight. The following morning rats were humanely sacrificed using thiopental anesthesia by I.P injection at a dose of $30-40 \mathrm{mg} / \mathrm{kg}$.

\section{Blood samples}

Cardiac puncture was performed to obtain blood samples from the heart. After collection of the blood in test tubes, some blood samples were left to clot for 30 minutes at room temperature then centrifuged at $4000 \mathrm{rpm}$ for 15 minutes in order to obtain serum samples. Other blood samples were collected using Heparin as an anticoagulant in order to obtain whole blood samples.

\section{Stomach specimens}

Each stomach was surgically removed and opened along the greater curvature, and the gastric content was evacuated and collected for the determination of its $\mathrm{pH}$. The stomach was unfolded and examined macroscopically and photographed beside a metric ruler for the assessment of the gastric lesions. The total stomach area and the ulcer area was then measured manually by a grid drawn on the photo of the stomach using the photographed metric ruler. The gastric mucosal damage was expressed in terms of ulcer index according to established equation [15].It depends on the calculation of the ulcer index by measuring the total surface area of the stomach and the surface area of the ulcerated region in square millimeters. Ulcer index was then calculated from the following equation:
Ulcer index $(\mathrm{U} . \mathrm{I})=[$ Ulcerated area/total stomach

$$
\text { area } \times 100
$$

Then, specimens were fixed in formalin for further histopathological examination.

\section{Determination of $\mathrm{pH}$ of the gastric contents}

A centrifuge tube was used to collect the gastric content, then it was centrifuged at $1000 \mathrm{rpm}$ for 10 min to remove any solid debris [16]. The clear supernatant was recovered and used for $\mathrm{pH}$ measurement using a pH 211 meter.

\section{Determination of Oxidative stress markers Malondialdehyde (MDA) and reduced glutathione (GSH)}

The MDA level in the serum was determined by using kits purchased from (company of Biodiagnostic, Egypt).A reaction between MDA and Thiobarbituric acid (TBA) occurs in acidic medium at $95{ }^{\circ} \mathrm{C}$ temperature for 30 minutes result in the formation of Thiobarbituric acid reactive product. By measuring the absorbance of the resultant pink product, MDA concentration can be determined [17].

The GSH level in the whole blood and erythrocyte lysate was determined by using kits purchased from (company of Bio-diagnostic, Egypt).GSH reduces 5, 5' dithiobis 2-nitrobenzoic acid (DTNB) yielding yellow compound. By measuring its absorbance, GSH concentration in the sample can be determined [18].

\section{Gastric morphology by hematoxylin and eosin.}

Samples obtained from the stomach of the sacrificed rats, were immediately scrubbed with normal saline and fixation done using buffered neutral formalin $(10 \%)$. After the tissue fixed properly, the samples were prepared by making 
paraffin blocks and sectioned then stained with hematoxylin and eosin and examined by light microscope.

\section{Casapse-3 (executioner of apoptosis) expression:}

Immunostaining was performed using the AvidineBiotin complex (ABC) method according to manufacturer's instructions [19].

\section{BCL-xl (anti-apoptotic marker) expression:}

immune reaction were performed according to manufacturer's instructions (Thermo Fisher scientific.UK) [20].Caspase-3 and BCL-xl expression was quantified using image $\mathrm{j}$ software

\section{Statistical analysis:}

Statistical analysis of the results was performed by the means of the statistical package for social science (SPSS) version 17. Normally distributed data was expressed as Mean $\pm \mathrm{SD}$, and Data were compared by Analysis Of Variance (ANOVA) with post hoc Tukey test (level of significance at $p$ value $<0.05)$. While, abnormally distributed data was expressed as median, minimum and maximum and Analysis was done by Kruskal-Wallis Test with Mann-Whitney Test (level of significance at $p$ value $<0.05$ ).

\section{Results:}

Macroscopic examination of gastric mucosa: ulcer number, area and ulcer index.

It was found that chronic unpredictable stress significantly increased the median ulcer number to 9 when compared to control group ( $p<$ 0.001). Also, the median ulcer number was significantly increased to 15 in AOAA treated group when compared to control group $(\mathrm{p}<$ 0.001). However, there was no significant difference between stressed group and AOAA treated group. On the other hand, the median ulcer number was significantly reduced to 2.5 in NaHS treated group in comparison with either stressed group or AOAA treated group $(\mathrm{p}=0.001, \mathrm{p}=$ 0.005 respectively), but was still significantly higher than control group $(\mathrm{p}=0.001)$; (Table $1 \&$ Figure 1).

Regarding the median ulcer area it was significantly increased to $12.5 \mathrm{~mm}^{2}$ in stressed group when compared to control group ( $\mathrm{p}<$ 0.001). Also, the median ulcer area was significantly increased to $46 \mathrm{~mm}^{2}$ in AOAA treated group when compared to both control and stressed groups ( $\mathrm{p}<0.001, \mathrm{p}=0.007$ respectively). On the other hand, the median the ulcer area was significantly reduced to $2 \mathrm{~mm}^{2}$ in NaHS treated group in comparison with either stressed group or AOAA treated group $(\mathrm{p}=0.002, \mathrm{p}=0.001$ respectively), but was still significantly higher than control group $(\mathrm{p}=0.001)$; (Table $1 \&$ Figure 1$)$.

Regarding the median ulcer index it was significantly increased to $1.698 \%$ in stressed group when compared to control group ( $\mathrm{p}<$ 0.001). Also, the median ulcer index was significantly increased to $5.3 \%$ in AOAA treated group when compared to both control and stressed groups ( $\mathrm{p}<0.001, \mathrm{p}=0.006$ respectively). On the other hand, the median the ulcer index was significantly reduced to $0.322 \%$ in NaHS treated group in comparison with either stressed group or AOAA treated group $(\mathrm{p}=0.001, \mathrm{p}=0.003$ respectively), but was still significantly higher than control group $(\mathrm{p}=0.001)$; $($ Table 1$)$.

\section{Gastric content pH}

Chronic unpredictable stress significantly decreased the mean $\mathrm{pH}$ value from $3.61 \pm 0.63$ to $2.74 \pm 0.6$ when compared to control group $(\mathrm{p}<$ 
$0.001)$. Also, the mean $\mathrm{pH}$ value was significantly decreased to $2.17 \pm 0.38$ in AOAA treated group when compared to control group ( $\mathrm{p}<0.001)$. However, there was no significant difference between AOAA treated and stressed groups. On the other hand, the mean $\mathrm{pH}$ value was significantly increased to $3.6 \pm 0.64$ in NaHS treated group in either comparison with stressed group or AOAA treated group $(\mathrm{p}=0.006, \mathrm{p}<$ 0.001 respectively). However, there was no significant deference between the control group and NaHS treated group (Figure 2a).

\section{Oxidative stress markers:}

It was found that chronic unpredictable stress significantly increased the mean MDA level from $37.58 \pm 5.76 \mathrm{nmol} / \mathrm{ml}$ to $81.49 \pm 14.13$ $\mathrm{nmol} / \mathrm{ml}$ when compared to control group $(\mathrm{p}<$ 0.001). Also, the mean MDA level was significantly increased to $99.8 \pm 11.15 \mathrm{nmol} / \mathrm{ml}$ in AOAA treated group when compared to control group and stressed group $(\mathrm{p}<0.001, \mathrm{p}=0.001$ respectively); (table 3, figure 14). On the other hand, the mean MDA level was significantly reduced to $46.6 \pm 4.99 \mathrm{nmol} / \mathrm{ml}$ in NaHS treated group in comparison with either stressed group or AOAA treated group $(\mathrm{p}<0.001)$. However, there was no significant difference with control group (Figure 2b).

Regarding GSH level, it was significantly decreased from $318.5 \pm 23.7 \mathrm{mg} / \mathrm{dl}$ to $219.25 \pm$ $38.77 \mathrm{mg} / \mathrm{dl}$ in stressed rats when compared to control group $(\mathrm{p}<0.001)$. Also, the mean GSH level was significantly decreased to $167.88 \pm 30.94$ $\mathrm{mg} / \mathrm{dl}$ in AOAA treated group when compared to control group and stressed group $(\mathrm{p}<0.001, \mathrm{p}=$ 0.004 respectively); (table 3 , figure 15 ). On the other hand, the mean GSH level was significantly increased to $308.62 \pm 33.63 \mathrm{mg} / \mathrm{dl}$ in NaHS treated group in comparison with either stressed group or AOAA treated group $(\mathrm{p}<0.001, \mathrm{p}<0.001$ respectively). However, there was no significant difference with control group (Figure 2c).
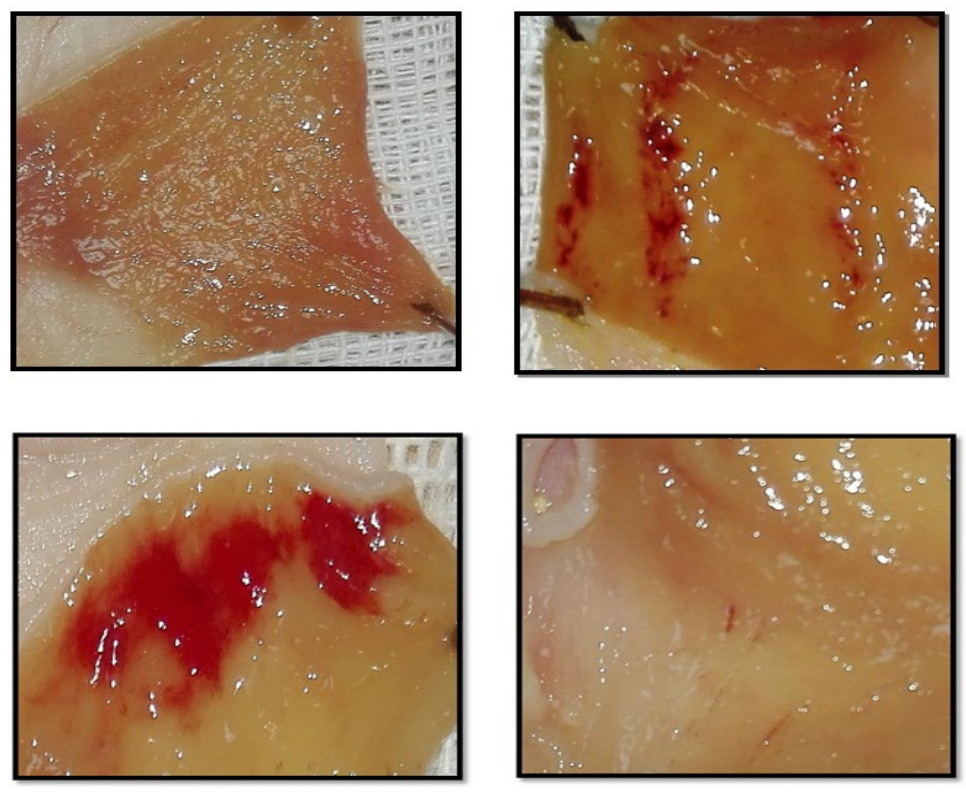

Figure (1): Macroscopic changes in the gastric mucosa from different studied groups. (a): The unfolded stomach from the control group. (b): The unfolded stomach from the stressed group, the arrows showing moderate gastric lesions. (c): The unfolded stomach from (stressed + AOAA) group, the arrows showing sever gastric lesions. (d): The unfolded stomach from (stressed $+\mathrm{NaHS}$ ) group, the arrows showing mild gastric lesions. 
Table (1):Values of ulcer number, ulcer area and ulcer index among control group, stressed group, stressed + AOAA group and stressed + NaHS group.

\begin{tabular}{cccccc}
\hline \multicolumn{2}{c}{ Groups } & Control & Stressed & $\begin{array}{c}\text { Stressed }+ \\
\text { AOAA }\end{array}$ & Stressed + NaHS \\
\hline Ulcer Number & Median & 0 & $9 *$ & $15 *$ & $2.5 * \# \mathbf{\$}$ \\
& Minimum & 0 & 6 & 2 & 0 \\
& Maximum & 0 & 15 & 20 & 6 \\
\hline $\begin{array}{c}\text { Ulcer area } \\
\left(\mathrm{mm}^{2}\right)\end{array}$ & Median & 0 & $12.5 *$ & $46 * \#$ & $2 * \# \mathbf{\$}$ \\
& Minimum & 0 & 3 & 13 & 0 \\
\hline Ulcer index & Maximum & 0 & 31 & 83 & 6 \\
$\begin{array}{c}\text { (ulcerated area } \\
\text { / total stomach } \\
\text { area) }\end{array}$ & Minimum & 0 & $1.698 *$ & $5.3 * \#$ & $0.322 * \# \mathbf{\$}$ \\
\hline \hline
\end{tabular}

Analysis was done by Kruskal-Wallis Test with Mann-Whitney Test. P $<0.05$ is considered significant. * Significant vs control group, \# significant vs stressed group,

\$ significant vs AOAA group
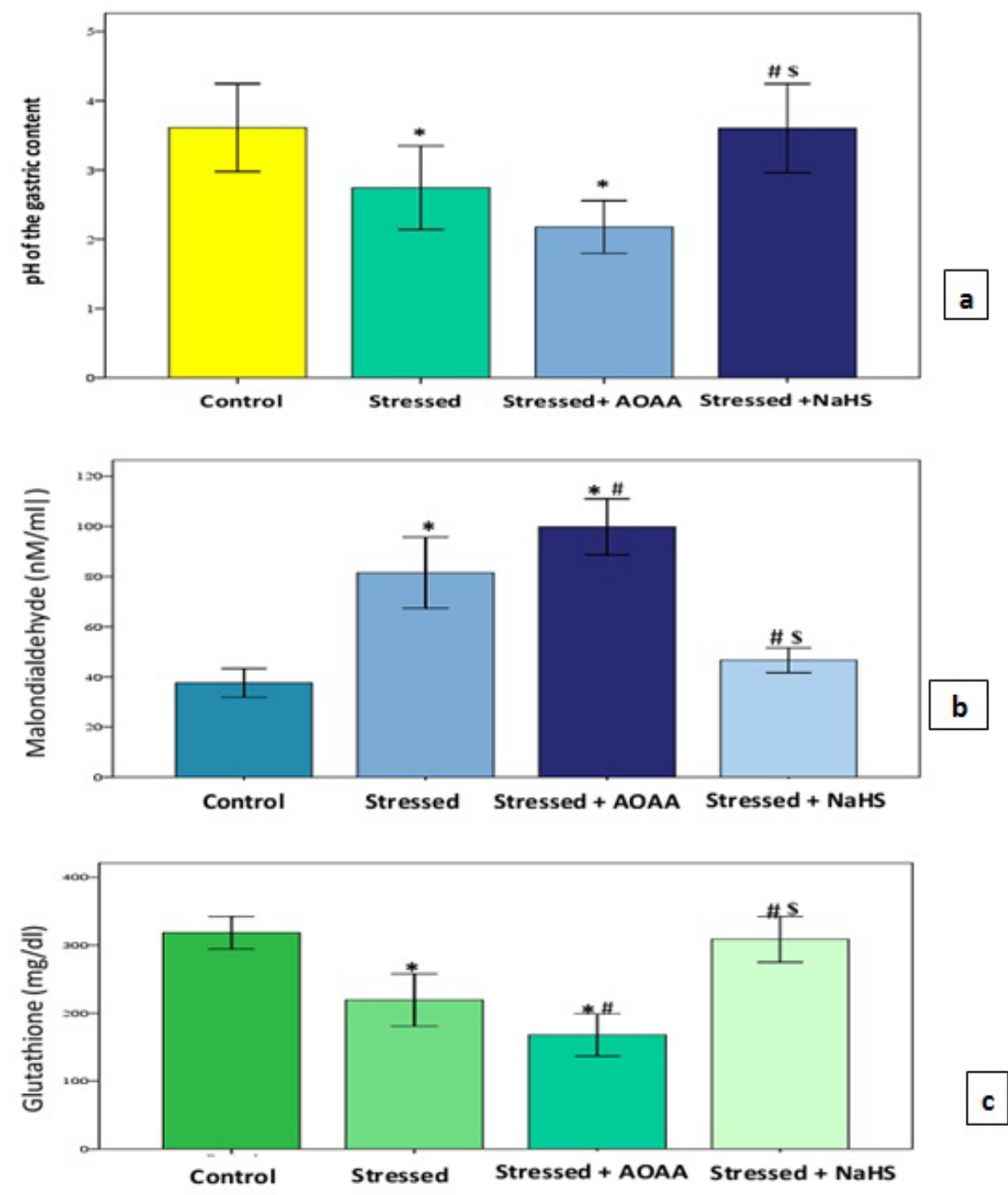

Figure (2): (a) $\mathrm{pH}$ value, (b) serum malondialdehyde and (c) whole blood glutathione in control group, stressed group, stressed + AOAA group and stressed + NaHS group. Each group $=8$ rats. $\mathrm{P}<0.05$ is significant (One Way ANOVA). * Significant vs control group. \# Significant vs stressed group. \$ Significant vs AOAA group 

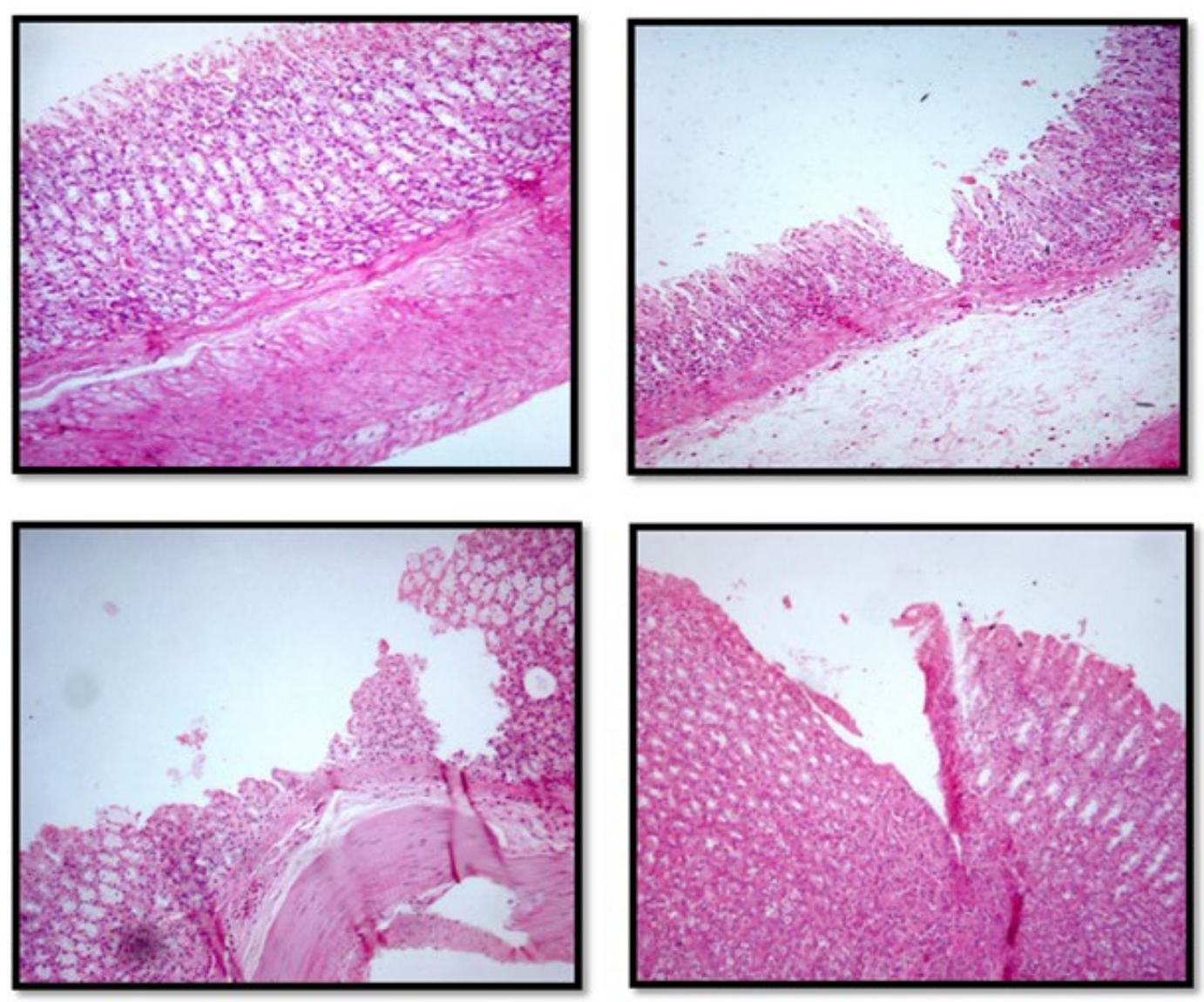

Figure (3): Histopathological examination of the gastric tissue samples using hematoxylin and eosin. (a): Control group showing normal gastric mucosa with no erosions or ulceration (H\&E x200 original magnification). (b): Stressed group showing severe erosions of the gastric epithelium with laminal infiltration by mild inflammatory cellular infiltrate (H\&E x100 original magnification). (c): (Stressed + AOAA) group showing very severe gastric ulceration and the base of the ulcer reaching muscularis mucosa with infiltration of the mucosa by oedema and inflammatory cells. (H\&E x100 original magnification). (d): (Stressed + NaHS) group showing gastric surface erosions with sub mucosal infiltration by oedema and inflammatory cells. (H\&E x200 original magnification). Arrows indicate gastric mucosal lesions.

\section{Microscopic examination of gastric mucosa:}

The histopathological examination of gastric mucosa revealed normal gastric mucosa with no erosions or ulceration in the control group. But gastric mucosa showed severe erosions of the gastric epithelium with laminal infiltration by mild inflammatory cellular infiltrate in the stressed group, that aggravated in the AOAA treated group, the ulcer reaching muscularis mucosa with infiltration of the mucosa by oedema and inflammatory cells. Whereas in the NaHS treated group, the gastric ulceration had reduced its intensity (Figure 3).

\section{Casapse-3 expression:}

The immunoreactivity to caspase- 3 in different studied groups showed that, the expression of caspase-3 was significantly higher in stressed group when compare to control group as caspase-3 expression increased from $5.499 \pm 0.643$ to $12.186 \pm 0.819(\mathrm{p}<0.001)$. Also, caspase-3 expression was significantly increased to $44.081 \pm$ 0.44 in AOAA treated group when compared to control group and stressed group $(\mathrm{p}<0.001)$. On the other hand, Caspase-3 expression was significantly reduced to $6.459 \pm 0.338$ in NaHS treated group in either comparison with stressed 
group or AOAA treated group $(\mathrm{p}<0.001, \mathrm{p}<$ 0.001 respectively); (Table $2 \&$ Figure 4 ).

\section{BCL-xl expression:}

The immunoreactivity to BCL-xl in different studied groups showed that, the expression of BCL-xl was significantly lower in stressed group when compare to control as it decreased from $16.201 \pm 0.320$ to $8.660 \pm 0.493$ ( $p$ $<$ 0.001). Also, BCL-xl expression was
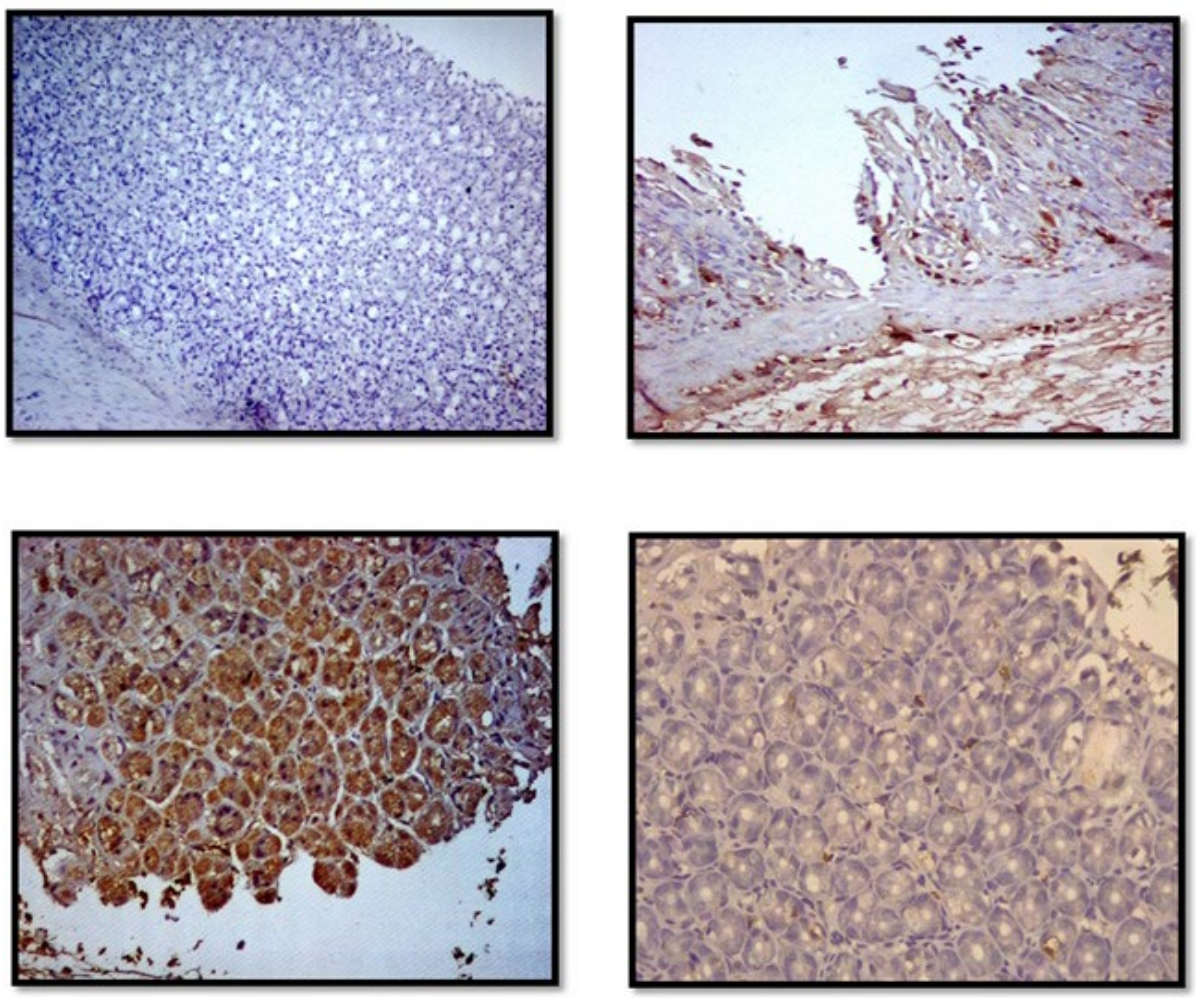

Figure (4): Immunohistochemistry for Caspase- 3 expression in the gastric mucosa of different studied groups. (a): Caspase-3 shows negative immunoreactivity in the intact gastric epithelium of control group. (b): Caspase-3 shows moderate immunoreactivity in the gastric epithelium of stressed group. (c): Caspase-3 shows positive cytoplasmic immunoreactivity of the gastric epithelium of (stressed + AOAA) group. (d): Caspase-3 shows mild immunoreactivity in the gastric epithelium of (stressed + NAHS) group.

Table 2: Quantification of Caspase-3 and BCL-xl by digital morphometric study in control group, stressed group, stressed + AOAA group and stressed + NaHS group

\begin{tabular}{|c|c|c|c|c|c|}
\hline Groups & $\mathrm{n}=8$ each & Control & Stressed & $\begin{array}{c}\text { Stressed + } \\
\text { AOAA }\end{array}$ & Stressed + NaHS \\
\hline Caspase-3 & Mean \pm SD & $5.499 \pm 0.643$ & $\begin{array}{l}12.186 \pm * \\
0.819\end{array}$ & $\begin{array}{l}44.081 \pm \\
* \#{ }_{0.44}\end{array}$ & $\begin{array}{c}6.459 \pm \# \$ \\
0.338\end{array}$ \\
\hline BCL-xl & Mean \pm SD & $16.201 \pm 0.320$ & $\begin{array}{l}8.660 \pm * \\
0.493\end{array}$ & $\begin{array}{l}3.4855 \pm \\
* \#{ }_{0.178}\end{array}$ & $\begin{array}{l}13.262 \pm \\
\# \text { \$ } 0.337\end{array}$ \\
\hline
\end{tabular}

Analysis was done by One Way ANOVA with post hoc Tukey's Test. $\mathrm{P}<0.05$ is considered significant. * Significant vs control group, \# significant vs stressed group, 

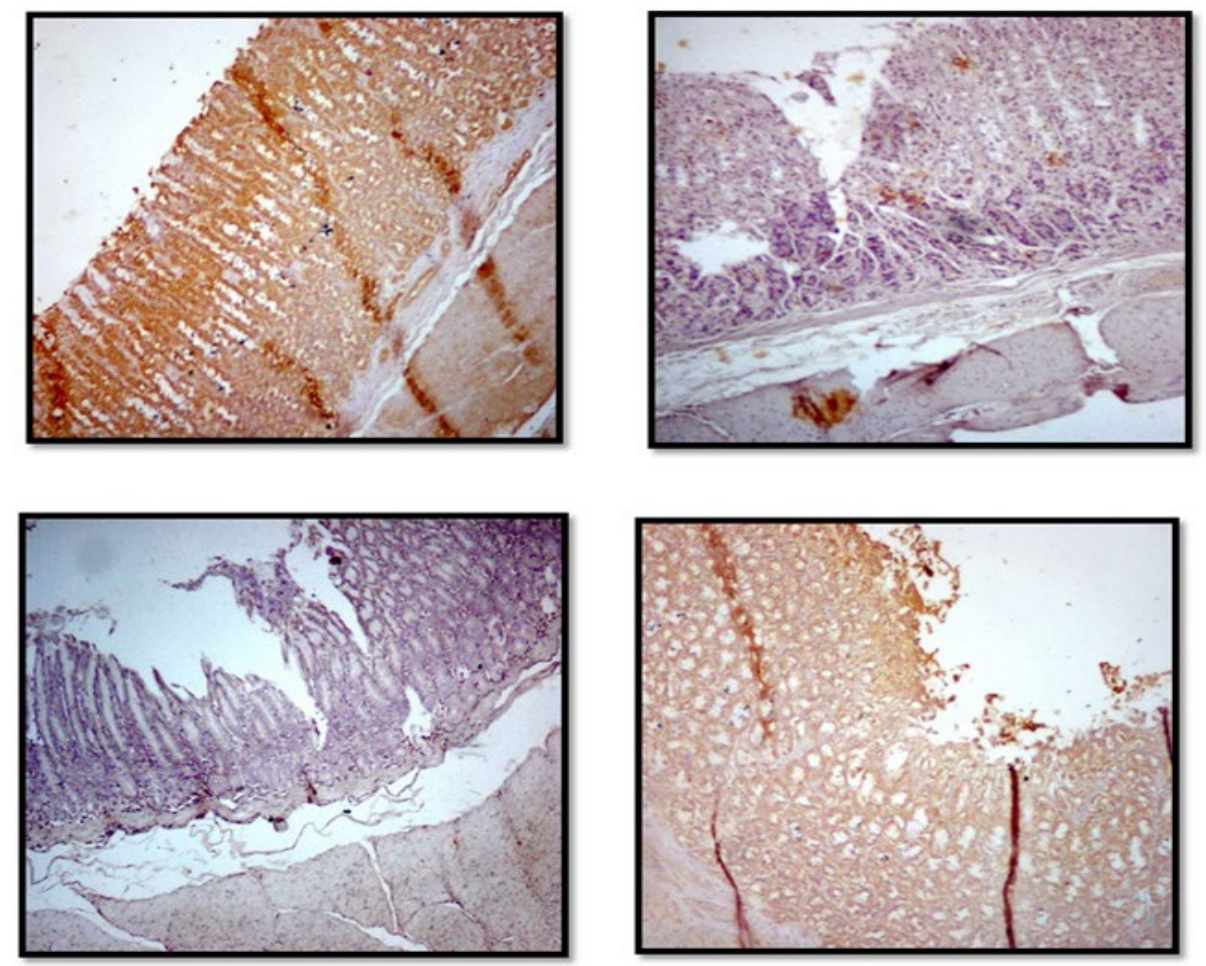

Figure (5): Immunohistochemistry for BCL-xl expression in the different studied groups. (a): BCL-xl shows positive cytoplasmic immunoreactivity in the intact gastric epithelium in the control group. (b): BCL-xl shows mild immunoreactivity in the gastric epithelium in stressed group. (c): BCL-xl shows negative immunoreactivity in the ulcerated gastric epithelium in (stressed + AOAA) group. (d): BCL-xl shows moderate immunoreactivity in the eroded gastric epithelium in (stressed $+\mathrm{NaHS}$ ) group

\section{Discussion}

A model of chronic unpredictable stress (CUS) was adopted in the present study. This protocol is well documented and has been widely used in small animals to induce gastric lesions [1, 4, 21]. In agreement with the previous studies, application of chronic stressors in rats for 6 weeks induced gastric lesions as evidenced by macroscopic and microscopic findings. The macroscopic changes were in the form of ulceration that were evaluated regarding its number, area and the ratio of the total ulcerated area to the total area of the unfolded stomach (ulcer index). CUS caused gastric ulcerations with significant number, area and index on macroscopic examination of the rat's unfolded stomach. Also, the microscopic examination of the gastric mucosa from CUS exposed rats revealed severe erosions of the gastric epithelium with laminal infiltration by mild inflammatory cellular infiltrate. In parallel with the morphological changes, CUS has increased the acidity of the gastric contents. Thus, the stress induced macroscopic and microscopic changes could be explained simply by the reduction in $\mathrm{pH}$ of the gastric content observed in stressed rats when compared to control group. A very early study [22] also explained similar findings by the increase in gastric $\mathrm{HCl}$ secretion without parallel increase of the gastric mucosal blood flow. A similar proposal had been presented by Kwiecien et al. [23]. Unfortunately, measuring the gastric blood flow was not tested in the present study, and hence it can't be considered. However, the reduction in the gastric $\mathrm{pH}$ was evident and investigating whether exposure to chronic stress 
could limit or reduce the gastric mucosal blood flow is an interesting point for future research.

In order to test the effect of $\mathrm{H}_{2} \mathrm{~S}$ on the previous findings, an indirect protocol was followed by injecting $\mathrm{NaHS}$ as a $\mathrm{H}_{2} \mathrm{~S}$ donor and AOAA as an inhibitor of $\mathrm{H}_{2} \mathrm{~S}$ synthesis. The use of $\mathrm{NaHS}$ as $\mathrm{H}_{2} \mathrm{~S}$ donor with CUS caused significant improvement in the stress induced morphological changes as observed by decreasing the ulcer number, area and index. Also, the use of NaHS has reduced the acidity of the collected gastric contents which further supports that excess $\mathrm{HCl}$ secretion is an important element in the stress-induced gastric lesions. Indeed, Wallace et al., (2007) has reported that administration of 1-cysteine, a precursor of endogenous $\mathrm{H}_{2} \mathrm{~S}$ synthesis or NaHS as $\mathrm{H}_{2} \mathrm{~S}$ donor resulted in enhanced healing of the gastric mucosal lesions. On the other hand, receiving AOAA as an inhibitor of $\mathrm{H}_{2} \mathrm{~S}$ synthesis with CUS has aggravated the stress-induced gastric lesions as observed by the increase in the ulcer area and index when compared to rats exposed to CUS only. AOAA was reported to be a strong inhibitor of both cystathionine- $\gamma$-lyase (CSE), cystathionine$\beta$-synthase (CBS) [24]. These two enzymes are responsible for much of the enzymatic endogenous generation of $\mathrm{H}_{2} \mathrm{~S}$ in the stomach [25].

As regard the $\mathrm{pH}$ of the gastric contents, the present study showed that rats exposed to CUS had significantly reduced gastric $\mathrm{pH}$ value when compared to control group. Grossman [26] had explained this increase in the gastric $\mathrm{HCl}$ secretion with stress by increasing the secretion of histamine and stimulation of the gastric acid secretion both sympathetically and parasympathetically during stress. The use of NaHS as $\mathrm{H}_{2} \mathrm{~S}$ donor with CUS had significantly elevated the gastric $\mathrm{pH}$ value suggesting a decrease in $\mathrm{HCl}$ secretion by the gastric mucosal cells. Further, NaHS has reduced the gastric acid secretion to a nearly normal value similar to its level in the control group. By contrast, samples from (stress + AOAA) group showed marked increase in the gastric acidity and drop of the $\mathrm{pH}$ value of the gastric content when compared to rats exposed to CUS only. These findings implicate a role of $\mathrm{H}_{2} \mathrm{~S}$ in the inhibition of the stress-induced increased gastric $\mathrm{HCl}$ secretion.

Indeed, the present experiments have shown indirectly that $\mathrm{H}_{2} \mathrm{~S}$ exerts an inhibitory effect on $\mathrm{HCl}$ secretion as evidenced by the change observed in $\mathrm{pH}$ of the gastric content. Such relation has been reported by Cheraghi et al. [27]. Also, Mard et al., (2015) used $\mathrm{H}_{2} \mathrm{~S}$ donor (NaHS) and $\mathrm{H}_{2} \mathrm{~S}$ percursor (L-cysteine) showing a reduction in the gastric $\mathrm{HCl}$ secretion in response to gastric distention. The possible mechanism of such effect of $\mathrm{H}_{2} \mathrm{~S}$ could be the increased release of nitric oxide in rats [28] which have been found to inhibit gastric acid secretion by acting directly on the parietal cell or indirectly by inhibiting the release of histamine [29, 30]. Also, VelázquezMoyado, Balderas-López [31] had reported that $\mathrm{H}_{2} \mathrm{~S}$ could participate in the production of bicarbonate wich in turn increases the $\mathrm{pH}$ of the gastric contents.

The present results also have shown that exposure to chronic stress leads to imbalance between the oxidant and antioxidant markers. The blood level of GSH as an anti-oxidant has been reduced in stressed rats with concomitant elevation in the serum MDA level. This imbalance was restored in rats receiving NaHS but worsened in rats receiving AOAA. Evidence from previous studies has shown that $\mathrm{H}_{2} \mathrm{~S}$ has anti-oxidant role 
by scavenging oxygen-derived free radicals [3234] or through regulation of Nuclear related factor 2 , which is the primary cellular defense against the cytotoxic effects of oxidative stress. Several studies have also proven that $\mathrm{H}_{2} \mathrm{~S}$ provide protection for the gastric mucosa by preserving the cellular GSH status and provides protection against oxidative damage in the gastrointestinal tract [35]. Such anti-oxidant role of $\mathrm{H}_{2} \mathrm{~S}$ is supported by the present findings.

The histopathological examination of the gastric tissue samples of the stressed rats has shown severe erosions of the gastric epithelium with laminal infiltration by mild inflammatory cellular infiltrate. Indeed, increasing the bioavailability of $\mathrm{H}_{2} \mathrm{~S}$ by the use of NaHS in stressed rats has reduced the severity of the gastric lesions and the inflammatory cell infiltration. This assumption is further supported by the finding that inhibition of $\mathrm{H}_{2} \mathrm{~S}$ synthesis by AOAA resulted in aggravating the severity of gastric lesions with stress. The fact that there was still a degree of surface erosions in samples from NaHS stressed rats might reflect the need of greater concentrations of $\mathrm{H}_{2} \mathrm{~S}$ to induce full gastric protection. Such possibility could be tested in future work. Inflammation of the gastric mucosa appears to be involved in the pathogenesis of various gastric mucosal injuries [36]. It has been reported that overexpression of interleukin-6 and tumor necrosis factor alpha are leading factors mediating neutrophil infiltration of gastric mucosa which further exacerbates ROS production[37].This anti-inflammatory effect of $\mathrm{H}_{2} \mathrm{~S}$ was also reported by Chen et al. and Zeng et al.[38, 39].
Indeed, the anti-inflammatory effect exerted by $\mathrm{H}_{2} \mathrm{~S}$ donor (NaHS) in the present experiments is in line with its effect on expression of the anti-apoptotic protein; BCL-xl. As shown in the result section of this study. Chronic stress not only induced gastric lesions by increasing the gastric $\mathrm{HCl}$ secretion but also led to increased expression of Caspase-3 (executioner of apoptosis) and decreased the expression of BCL-xl. BinJaliah [4] reported similar results but with only 3 weeks of CUS.

In general, two major pathways can induce apoptotic cell death; the intrinsic, mitochondrial. Both pathways converge to a final apoptosis execution step which includes Caspase 3. So, Caspase-3 is considered to be a major executioner protease which is essential for apoptotic death in mammalian cells [40]. On the other hand, BCL-xl is an anti-apoptotic member of the BCL-2 family. BCL-xl prevents apoptosis by inhibiting release of cytochrome c into the cytoplasm [41]. Indeed, previous studies have reported that $\mathrm{H}_{2} \mathrm{~S}$ exerts its anti-apoptotic effects in the circulatory and nervous system [42]. However, very scares information exists about such role in the GIT. Yan and $\mathrm{Li}$ [10] highly suggested a possible antiapoptotic role of $\mathrm{H}_{2} \mathrm{~S}$ in the gastric tissue, whereas $\mathrm{Lu}, \mathrm{Gao}$ [43] demonstrated that persistent exposure to $\mathrm{H}_{2} \mathrm{~S}$ could induce apoptosis inside the gastric tissue. A possible explanation for this controversy is that normal cellular homeostasis is maintained through a balance between the processes of cell proliferation and cell death. Accordingly, $\mathrm{H}_{2} \mathrm{~S}$ donors could act as apoptotic agents by selectively inducing apoptotic cell death in diseased cells without causing damage to normal cells [44]. 


\section{Conclusion:}

The major aim of the present study was to investigate the role of $\mathrm{H}_{2} \mathrm{~S}$ in protection against chronic unpredictable stress-induced gastric lesions in rats, through the use of NaHS as $\mathrm{H}_{2} \mathrm{~S}$ donor and AOAA as an inhibitor of $\mathrm{H}_{2} \mathrm{~S}$ synthesis. The results of the present study suggest that increasing the bioavailability of $\mathrm{H}_{2} \mathrm{~S}$ could protect against CUS induced gastric lesions. This protective role of $\mathrm{H}_{2} \mathrm{~S}$ seems to be mediated through its inhibitory effect over the gastric $\mathrm{HCl}$ secretion, its anti-oxidant and its antiinflammatory effect with concomitant enhancement of the gastric anti apoptotic protein BCL-xl and inhibition of the apoptotic executioner protein Caspase-3.

Acknowledgements: Physiology Department and Medical Experimental Research Center of Mansoura University are acknowledged for their significant contribution to the experimental part of the study. A special thanks for Dr. Rokia Masoud, assistant lecturer in pathology department, Mansura University for her help in the histopathological examination.

Author contribution: Experimental work, data collection and paper writing was carried out by Mahmoud El tohamy, Mohamed Ghalwash, Nisreen Mansour Omar. \& Refka Khalil Messiha . Animal handling was done by Samah awad \& Mahmoud El Tohamy

Conflict of interest: The authors declare that there is no conflict of interest.

\section{References:}

1. Guo, S., Q. Gao, Q. Jiao, W. Hao, X. Gao, and J.-M. Cao: Gastric mucosal damage in water immersion stress: mechanism and prevention with GHRP-6. World journal of gastroenterology: WJG, 18(24): p. 3145, 2012.

2. Dobson, H. and R. Smith: What is stress, and how does it affect reproduction? Animal reproduction science, 60: p. 743$752,2000$.

3. Magierowski, M., K. Jasnos, S. Kwiecien, D. Drozdowicz, M. Surmiak, M. Strzalka, A. Ptak-Belowska, J.L. Wallace, and T. Brzozowski: Endogenous prostaglandins and afferent sensory nerves in gastroprotective effect of hydrogen sulfide against stress-induced gastric lesions. PloS one, 10(3): p. e0118972, 2015.

4. Bin-Jaliah, I.: Remedial Effects of Resveratrol on Chronic Unpredictable Stress-Induced Gastric Lesions in Male Albino Rats. Bull. of Egyp. Soc. Physiol. Sci., 35(3): p. 46-61, 2015.

5. Cook, D.J., H.D. Fuller, G.H. Guyatt, J.C. Marshall, D. Leasa, R. Hall, T.L. Winton, F. Rutledge, T. Todd, and P. Roy: Risk factors for gastrointestinal bleeding in critically ill patients. New England journal of medicine, 330(6): $\mathrm{p}$. 377-381, 1994.

6. Cook, D.J., L.E. Griffith, S.D. Walter, G.H. Guyatt, M.O. Meade, D.K. Heyland, A. Kirby, and M. Tryba: The attributable mortality and length of intensive care unit stay of clinically important gastrointestinal bleeding in critically ill patients. Critical care, 5(6): p. 368, 2001.

7. Wang, R.: Two's company, three'sa crowd: can $\mathrm{H} 2 \mathrm{~S}$ be the third endogenous 
gaseous transmitter? The FASEB journal, 16(13): p. 1792-1798, 2002.

8. Predmore, B.L., D.J. Lefer, and G. Gojon: Hydrogen sulfide in biochemistry and medicine. Antioxidants \& redox signaling, 17(1): p. 119-140, 2012.

9. Linden, D.R., M.D. Levitt, G. Farrugia, and J.H. Szurszewski: Endogenous production of $\mathrm{H} 2 \mathrm{~S}$ in the gastrointestinal tract: still in search of a physiologic function. Antioxidants \& redox signaling, 12(9): p. 1135-1146, 2010.

10. Yan, X. and D. Li: The protect role of Hydrogen sulfide in gastric injury. Inflammation and Cell Signaling, 1(2), 2014

11. Liu, Y.-Y., A. Sparatore, P. Del Soldato, and J.-S. Bian: ACS84, a novel hydrogen sulfide-releasing compound, protects against amyloid $\beta$-induced cell cytotoxicity. Neurochemistry international, 58(5): p. 591-598, 2011.

12. Zhang, M., H. Shan, P. Chang, T. Wang, W. Dong, X. Chen, and L. Tao: Hydrogen sulfide offers neuroprotection on traumatic brain injury in parallel with reduced apoptosis and autophagy in mice. PLoS One, 9(1): p. e87241, 2014.

13. Xiao, A., H. Wang, X. Lu, J. Zhu, D. Huang, T. Xu, J. Guo, C. Liu, and J. Li: H $2 \mathrm{~S}$, a novel gasotransmitter, involves in gastric accommodation. Scientific reports, 5: p. 16086, 2015.

14. Harro, J., R. Häidkind, M. Harro, A.-R. Modiri, P.-G. Gillberg, R. Pähkla, V. Matto, and L. Oreland: Chronic mild unpredictable stress after noradrenergic denervation: attenuation of behavioural and biochemical effects of DSP-4 treatment.

European

Neuropsychopharmacology, 10(1): p. 516, 1999.

15. Sabiu, S., T. Garuba, T. Sunmonu, E. Ajani, A. Sulyman, I. Nurain, and A. Balogun: Indomethacin-induced gastric ulceration in rats: Protective roles of Spondias mombin and Ficus exasperata. Toxicology reports, 2: p. 261-267, 2015.

16. El-Ashmawy, N.E., E.G. Khedr, H.A. El-Bahrawy, and H.M. Selim: Gastroprotective effect of garlic in indomethacin induced gastric ulcer in rats. Nutrition, 32(7): p. 849-854, 2016.

17. Kei, S.: Serum lipid peroxide in cerebrovascular disorders determined by a new colorimetric method. Clinica chimica acta, 90(1): p. 37-43, 1978.

18. Beutler, E.: Improved method for determination of blood glutathione. J Lab Clin Med, 61(5): p. 882-888, 1963.

19. Wydooghe, E., L. Vandaele, J. Beek, H. Favoreel, B. Heindryckx, P. De Sutter, and A. Van Soom: Differential apoptotic staining of mammalian blastocysts based on double immunofluorescent CDX2 and active caspase-3 staining. Analytical biochemistry, 416(2): p. 228-230, 2011.

20. Emily, H.-Y.C., M.C. Wei, S. Weiler, R.A. Flavell, T.W. Mak, T. Lindsten, and S.J. Korsmeyer: BCL-2, BCL-XL sequester $\mathrm{BH} 3$ domain-only molecules preventing $\mathrm{BAX}$-and $\mathrm{BAK}$-mediated mitochondrial apoptosis. Molecular cell, 8(3): p. 705-711, 2001.

21. Kamper, E., A. Chatzigeorgiou, 0. Tsimpoukidi, M. Kamper, C. Dalla, P. Pitychoutis, and Z. PapadopoulouDaifoti: Sex differences in 
oxidant/antioxidant balance under a chronic mild stress regime. Physiology \& behavior, 98(1-2): p. 215-222, 2009.

22. Kitagawa, H., M. Fujiwara, and $Y$. Osumi: Effects of water-immersion stress on gastric secretion and mucosal blood flow in rats. Gastroenterology, 77(2): p. 298-302, 1979.

23. Kwiecien, S., M. Pawlik, T. Brzozowski, W. Pawlik, and S. Konturek: Reactive oxygen metabolite action in experimental, stress model of gastric mucosa damage. Gastroenterol Pol, 17: p. 234-243, 2010.

24. Asimakopoulou, A., P. Panopoulos, C.T. Chasapis, C. Coletta, Z. Zhou, G. Cirino, A. Giannis, C. Szabo, G.A. Spyroulias, and A. Papapetropoulos: Selectivity of commonly used pharmacological inhibitors for cystathionine $\beta$ synthase (CBS) and cystathionine $\gamma$ lyase (CSE). British journal of pharmacology, 169(4): p. 922932, 2013.

25. Wallace, J.L., M. Dicay, W. McKnight, and G.R. Martin: Hydrogen sulfide enhances ulcer healing in rats. The FASEB Journal, 21(14): p. 4070-4076, 2007.

26. Grossman, M.: Control of gastric secretion. GastroIntestInal Disease, Pathophysiology, Diagnosis and Management ,G. Sleisenger and J.S. Fordtran (Eds.) W.B. Saunders Co., Philadelphia, p. 640-659, 1978.

27. Cheraghi, P., S.A. Mard, and T. Nagi. Hydrogen sulfide upregulated mRNA expressions of Sodium bicarbonate cotransporter1, Trefoil factor1 and Trefoil factor2 in gastric mucosa in rats. in
Veterinary Research Forum: 7(4): $323-$ 328, 2016.

28. Ise, F., H. Takasuka, S. Hayashi, K. Takahashi, M. Koyama, E. Aihara, and K. Takeuchi: Stimulation of duodenal HCO3 - secretion by hydrogen sulphide in rats: Relation to prostaglandins, nitric oxide and sensory neurones. Acta Physiologica, 201(1): p. 117-126, 2011.

29. Berg, A., S. Redeen, A.-C. Ericson, and S.E. Sjöstrand: Nitric oxide-an endogenous inhibitor of gastric acid secretion in isolated human gastric glands. BMC gastroenterology, 4(1): p. 16, 2004.

30. Berg, A., S. Kechagias, S.-E. Sjöstrand, and A.-C. Ericson: Morphological support for paracrine inhibition of gastric acid secretion by nitric oxide in humans. Scandinavian journal of gastroenterology, 36(10): p. 1016-1021, 2001.

31. Velázquez-Moyado, J.A., J.L. BalderasLópez, E.A. Pineda-Peña, B.L. SánchezOrtiz, J.C. Tavares-Carvalho, and A. Navarrete: Diligustilide releases H 2 S and stabilizes S-nitrosothiols in ethanolinduced lesions on rat gastric mucosa. Inflammopharmacology, 26(2): p. 611619, 2018.

32. Lu, M., L.-F. Hu, G. Hu, and J.-S. Bian: Hydrogen sulfide protects astrocytes against $\mathrm{H} 2 \mathrm{O} 2$-induced neural injury via enhancing glutamate uptake. Free Radical Biology and Medicine, 45(12): p. 17051713, 2008.

33. Geng, B., L. Chang, C. Pan, Y. Qi, J. Zhao, Y. Pang, J. Du, and C. Tang: Endogenous hydrogen sulfide regulation of myocardial injury induced by isoproterenol. Biochemical and 
biophysical research communications, 318(3): p. 756-763, 2004.

34. Elrod, J.W., J.W. Calvert, J. Morrison, J.E. Doeller, D.W. Kraus, L. Tao, X. Jiao, R. Scalia, L. Kiss, and C. Szabo: Hydrogen sulfide attenuates myocardial ischemia-reperfusion injury by preservation of mitochondrial function. Proceedings of the National Academy of Sciences, 104(39): p. 15560-15565, 2007.

35. Bronowicka-Adamska, P., M. Wróbel, M. Magierowski, K. Magierowska, S. Kwiecień, and T. Brzozowski: Hydrogen sulphide production in healthy and ulcerated gastric mucosa of rats. Molecules, 22(4): p. 530, 2017.

36. Odashima, M., M. Otaka, M. Jin, K. Komatsu, I. Wada, Y. Horikawa, T. Matsuhashi, N. Hatakeyama, J. Oyake, and R. Ohba: Attenuation of gastric mucosal inflammation induced by aspirin through activation of $\mathrm{A} 2 \mathrm{~A}$ adenosine receptor in rats. World Journal of Gastroenterology: WJG, 12(4): p. 568, 2006.

37. Yoshikawa, T. and Y. Naito: The role of neutrophils and inflammation in gastric mucosal injury. Free radical research, 33(6): p. 785-794, 2000.

38. Chen, Y.-H., P.-P. Wang, X.-M. Wang, Y.-J. He, W.-Z. Yao, Y.-F. Qi, and C.-S. Tang: Involvement of endogenous hydrogen sulfide in cigarette smoke- induced changes in airway responsiveness and inflammation of rat lung. Cytokine, 53(3): p. 334-341, 2011.

39. Zeng, J., X. Lin, H. Fan, and C. Li: Hydrogen sulfide attenuates the inflammatory response in a mouse burn injury model. Molecular medicine reports, 8(4): p. 1204-1208, 2013.

40. Said, T.M., U. Paasch, H.J. Glander, and A. Agarwal: Role of caspases in male infertility. Human Reproduction Update, 10(1): p. 39-51, 2004.

41. MacLeod, R.J.: MDR-1, Bcl-xL, H. pylori, and $\mathrm{Wnt} / \beta$-catenin signalling in the adult stomach: how much is too much? Nature Publishing Group, 2012

42. Hu, L.-F., M. Lu, Z.-Y. Wu, P.T.-H. Wong, and J.-S. Bian: Hydrogen sulfide inhibits rotenone-induced apoptosis via preservation of mitochondrial function. Molecular pharmacology, 75(1): p. 27-34, 2009.

43. Lu, S., Y. Gao, X. Huang, and X. Wang: GYY4137, a hydrogen sulfide (H2S) donor, shows potent anti-hepatocellular carcinoma activity through blocking the STAT3 pathway. International journal of oncology, 44(4): p. 1259-1267, 2014.

44. Wu, D., W. Si, M. Wang, S. Lv, A. Ji, and Y. Li: Hydrogen sulfide in cancer: Friend or foe? Nitric Oxide, 50: p. 38-45, 2015. 